\title{
Optical Absorption Spectra of Ruby and Periclase at High Shock Pressures ${ }^{1}$
}

\author{
Edward S. Gaffney ${ }^{2}$ and Thomas J. Ahrens \\ Seismological Laboratory, California Institute of Technology, Pasadena, California 91109
}

\begin{abstract}
A spectrographic system is described that is capable of measuring optical absorption spectra in solids to shock pressures of several hundred kilobars. The system utilized light from a 'point' source at about $60,000^{\circ} \mathrm{K}$. Spectra have a resolution of about $40 \mathrm{~A}$ and cover the visible range. With a streak camera, time resolution of about 75 nsec can be obtained. The spectrum of $\mathrm{MgO}$ is observed to remain featureless at $450 \mathrm{~kb}$ and upon unloading from this pressure. The color centers observed in shock-recovered material must result from either higher pressures or other processes. The optical absorption spectra of ruby under shock compressions of almost $15 \%$ have been measured in the range $375-600 \mathrm{~nm}$. Below the elastic limit the large anisotropic strains are evident from the splitting of the ${ }^{4} \mathrm{~A}_{9} \rightarrow{ }^{4} \mathrm{~T}_{2}(\mathrm{~F})$ absorption band by $3730 \mathrm{~cm}^{-1}$. Above the elastic limit this splitting is not resolved (but must be less than $800 \mathrm{~cm}^{-7}$ ), indicating considerable loss of shear strength in such cases. Above the Hugoniot elastic limit up to pressures of $530 \mathbf{~ k b}$ ( $15 \%$ volume compression) the measured value of the crystal field parameter agrees, within experimental error, with the value calculated from a point charge model $\left(D q \propto r^{-5}\right)$ if the local compressibility is equal to the bulk compressibility. This result agrees with Stephens and Drickamer's absorption data up to $150 \mathrm{~kb}$ and suggests that the point charge model is useful in predicting crystal field effects in mantle minerals, especially those having similar oxygen anion packings such as corundum.
\end{abstract}

The absorption spectra of minerals at very high pressures are of considerable importance to the problem of the behavior of $\mathrm{Fe}^{2+}$ in the interior of the earth. Specifically, measurements of the pressure shifts of absorption bands, both spin allowed and spin forbidden, over a range of several hundred kilobars provide an experimental basis for the prediction of crystal field effects in the minerals of the lower mantle [Gaffiney, 1972; Burns, 1970]. Under lower mantle conditions (temperatures of $1800^{\circ}$ $4000^{\circ} \mathrm{K}$ and pressures of $300-1400 \mathrm{~kb}$ ) heat transport by radiation is thought to be an important phenomenon in this region [Clark, 1957; Pitt and Tozer, 1970; Schatz and Simmons, 1972]. This belief arises primarily from the coincidence of the maximum of the universal blackbody radiation function in this temperature range with a minimum of the absorption spectra af many silicates and oxides. The

\footnotetext{
${ }^{1}$ Contribution 2232, Division of Geological and Planetary Sciences, California Institute of Technology.

Now at Systems, Science and Software, La Jolla, California 92037.
}

Copyright (C) 1973 by the American Geophysical Union. bounds on this minimum are the metal-oxygen charge transfer bands in the ultraviolet and the vibrational absorptions in the infrared. Thus, except for the interference of electronic absorptions, due mainly to crystal field effects on transition metal impurities, principally $\mathrm{Fe}^{++}$, thermal transport in oxides and silicates at temperatures in excess of $1500^{\circ} \mathrm{C}$ is probably strongly affected by the radiative conductivity. To predict the thermal properties of the earth's mantle, it is important, therefore, to be able to account for the effects of both temperature and pressure on these electronic absorptions. (Movements of the charge transfer peaks can also be seen in absorption spectra. The bands may have an important effect on radiative transfer. The reader is referred to the discussions by Pitt and Tozer [1970] and Gaffney [1972].)

If a phase change should occur while experiments are being carried out in the pressure region of interest, it is likely that the local site symmetry of $\mathrm{Fe}^{2+}$ in the high-pressure phase could be determined from its absorption spectrum. In many cases such a knowledge, combined with the knowledge of the density of the high-pressure phase, could unequivocably determine the structure of that phase. 
For these reasons we developed a system capable of measuring optical absorption spectra of minerals while they are in a dynamically produced, high-pressure shock state. Our system is described and its present capabilities illustrated in the discussion of results for periclase and ruby.

\section{Experimental TeChNique}

Time-resolved spectral measurements of a solid during shock loading have not been performed previously, although single-frame spectra of shocked liquids [David and Ewald, 1960] and time-resolved spectra of shocked liquids [Yakusheva et al., 1971] using explosive argon light sources have been reported. The use of such explosive sources is not practicable in a shock facility such as that at Caltech, where a high-performance gun is used to accelerate flyer plates that produce intense shock waves in minerals upon impact. The spectrograph system described below, although specifically designed for use in our system, could be adapted for use with most shock facilities, including those using high explosives. Briefly, light from an electrical arc discharge is focused on the sample by an optic system and is internally reflected back along a similar path (Figure 1). The ingoing and outcoming rays diverge slightly $\left(13^{\circ}\right)$ and permit the latter to be focused on the entrance slit of a simple reflection grating spectrograph. The exit part of the spectrograph is a slit, elongated in the direction of dispersion, which is the object scene for a streak camera. The resulting image is a plot of light intensity as a function of wavelength and time.

Light source. The light source is a confined electric discharge in air and is viewed axially

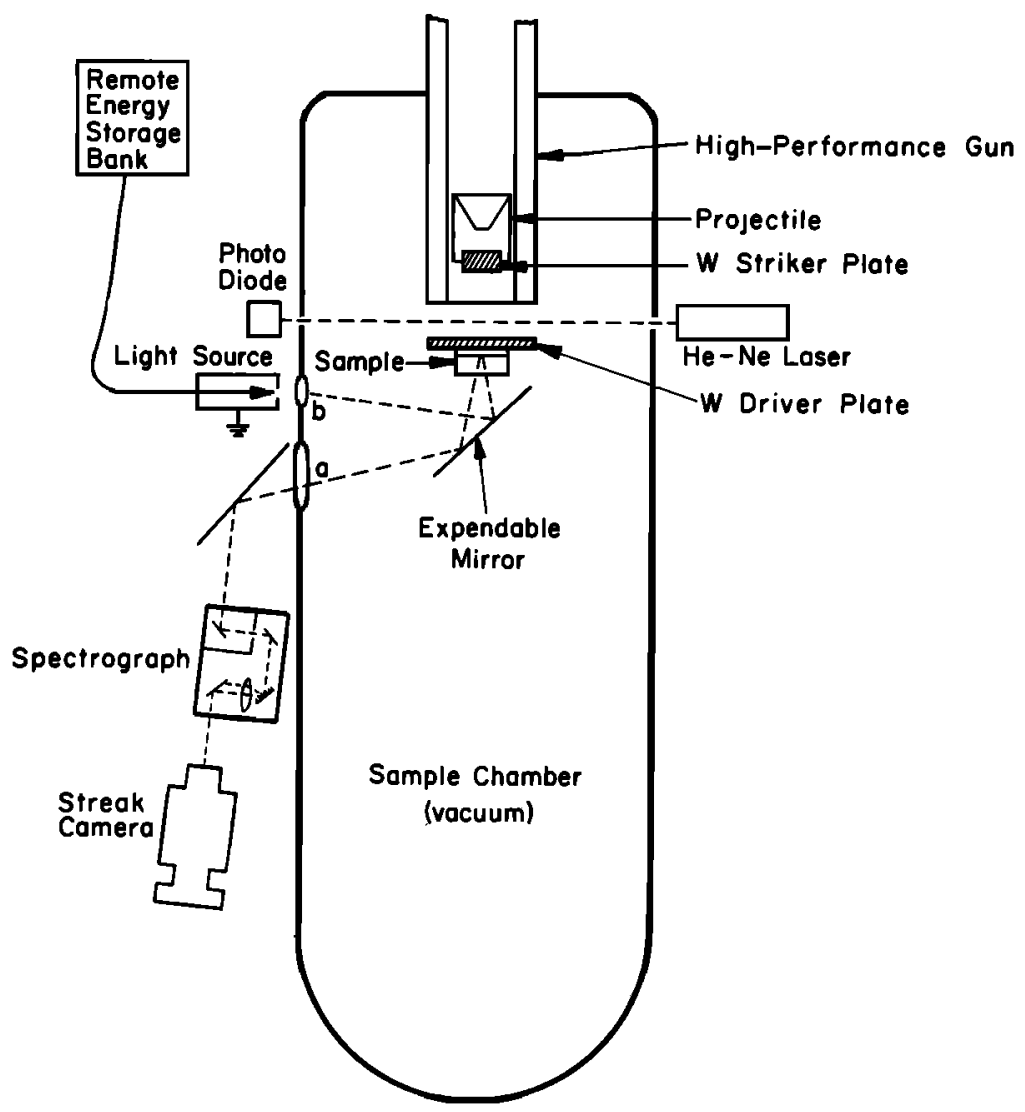

Fig. 1. Schematic cross section of spectrographic system designed to measure optical absorption spectra during shock loading to pressures in excess of $500 \mathrm{~kb}$. Lens $a$ is $308 \mathrm{~mm}$, $f / 2.5$; lens $b$ has a positive meniscus of $58 \mathrm{~mm}$ and a 7.5 diopter. 


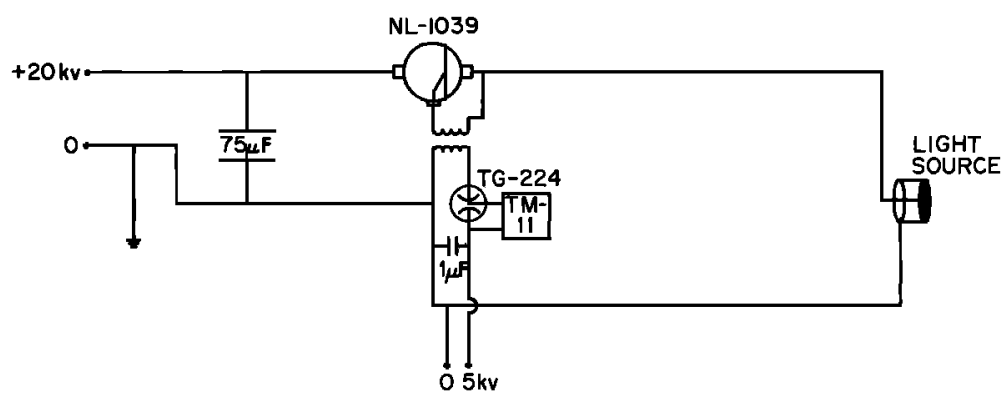

Fig. 2. Circuit diagram of a high-intensity point light source used to measure spectra in shocked solids. Components are described in Table 1.

through the ground electrode. The design is modified from that of Preonas and Swift [1970]. The electrical energy is stored at $20 \mathrm{kv}$ in a $75-\mu \mathrm{F}$ capacitor bank $(15,000$ joules $)$. The circuit is shown in Figure 2, and the components are described in Table 1 . The discharge is between a central copper electrode and a ground electrode (copper or tungsten alloy $(90 \% \mathrm{~W}$, $6 \% \mathrm{Cu}, 4 \% \mathrm{Ni}$ )) with an axial hole (Figure 3 ) separated about $1.6 \mathrm{~mm}$ by a lexan spacer. This spacer serves a dual purpose; it confines the arc and thus increases the energy density, and it is a source of carbon to produce a smooth spectrum.

Figure 4 shows a typical voltage time trace from the ignitron anode to ground. In this case the capacitor bank was at $19.5 \mathrm{kv}$ prior to discharge. From the oscillation frequency and damping of this curve the arc resistance is estimated to be of the order of $0.1 \mathrm{ohm}$. The intensity of this discharge was monitored with a red-sensitive photodiode (HP-4220) and is shown in Figure $4 b$. The flatness of the curve between 25 and $45 \mu \mathrm{sec}$ is not real but is produced by saturation of the diode. The peak intensity is probably within about $10 \%$ of the value of saturation. Comparison of the curve in Figure $4 d$ with that in Figure $4 b$ illustrates the sensitivity of light intensity to the detailed geometry of the gap. In the case of Figure $4 b$, the hole in the electrode was $1.6 \mathrm{~mm}$ in diameter, whereas in Figure $4 d$ it was about $3.2 \mathrm{~mm}$. The ignitron anode voltage curves for the two cases are indistinguishable. Apparently, the large volume available to the arc in the second case permits it to cool much more rapidly during low current episodes. At $20 \mathrm{kv}$ the light has a temperature of about $60,000^{\circ} \mathrm{K}$ and a peak intensity (red light) of about $5 \times 10^{a}$ $\mathrm{w} / \mathrm{cm}^{2}$. (Use of the manufacturer's 'typical sensitivity' of the photodiode and calibration of the diode relative to the sun on a clear day yield results within about $10 \%$ of one another.)

Spectrograph and camera. The spectrograph used (Figure 5) has a linear dispersion at the exit port of about $100 \mathrm{~A} / \mathrm{mm}$. The exit

TABLE 1. Components of Light Source

\begin{tabular}{|c|c|}
\hline Component & Description \\
\hline $\begin{array}{l}\text { Power supply (main) } \\
\text { Capacıtor bank } \\
\text { Switching ignitron (NL-1039) } \\
\text { Power supply (trigger) } \\
\text { Triggered spark gap (TG-224) } \\
\text { Trigger module (TM-11) } \\
\text { Cable } \\
\text { Transformer }\end{array}$ & $\begin{array}{l}\text { Universal Voltronics control, } 0 \text { - to } 32-\mathrm{kv} \text { direct current } \\
\text { (reversible), } 25 \text { ma. } \\
5 \text { Aerovox } 15-\mu \mathrm{F} 20-\mathrm{kv} \text { energy storage capacitors in parallel. } \\
\text { National NL-1039 1gnitron, } 20-\mathrm{kv} \text { peak anode voltage, 100-ka } \\
\text { peak current, air cooled. } \\
\text { Beckman } 1150-10 \text { to } 10 \mathrm{kv} \text { (reversible), } 9 \mathrm{ma} \text {. } \\
\text { Signalite TG-224, } 0.5 \text { to } 18 \mathrm{kv}, 6 \mathrm{kllojoules,} \mathrm{triggered} \mathrm{spark} \\
\text { gap. } \\
\text { EG\&G TM-11 trigger module, 0- to } 30-\mathrm{kv} \text { output remote trigger. } \\
\text { RG-22l, 14-kv } 50-\text { ohm coaxial cable (armored). } \\
\text { Three turns of coaxial cable (RGl4/U), ignitron on center } \\
\text { conductor. }\end{array}$ \\
\hline
\end{tabular}




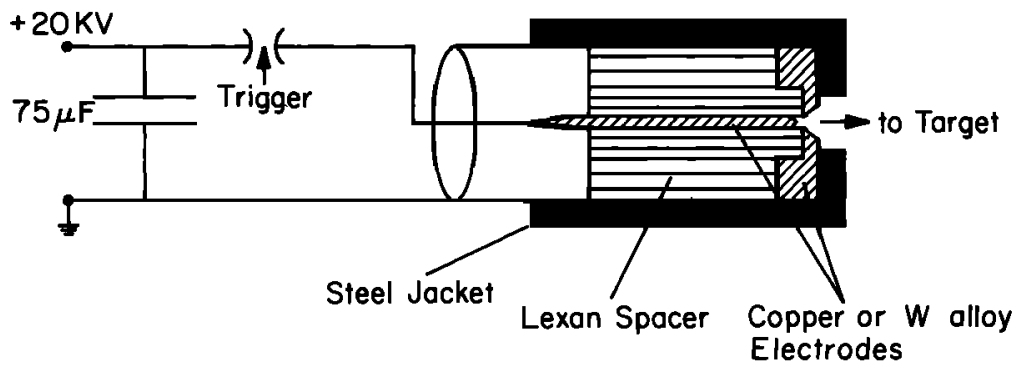

Fig. 3. Detail of the electrode configuration of high-intensity point light source.

port is a slit $0.5 \mathrm{~mm}$ wide and about $10 \mathrm{~cm}$ long in the direction of dispersion. The grating can be changed to give other values of dispersion, although greater dispersion is possible only by sacrificing already limited light intensity. Wavelength calibration of all records after the first one was achieved with a pulsed argon laser (TRW model 71A).

The TRW (model 1D) image converter streak camera used in the present system operates with an S-11 photocathode. Effective time and wavelength resolutions of 75 nsec and $40 \mathrm{~A}$ are achieved. This limitation on the system is the most stringent because of the narrow spectral sensitivity of this surface $(0.4-0.63$ $\mu \mathrm{m})$. The spectral response of the system is shown in Figure 6. The S-20 photocathode available on the same model camera would be preferable because of its greater sensitivity (about 50\% greater) and slightly wider response. Of the various surfaces now available, one of the GaAs surfaces such as RCA's 128 or 134 would be best if it were available because of the sensitivity and flatness throughout the visible part of the spectrum.

Sample. The sample configuration used with this system is shown in Figure 7. The sample is a gem quality single crystal polished on two parallel sides, one of which is aluminized to form a back surface mirror. The sample is a

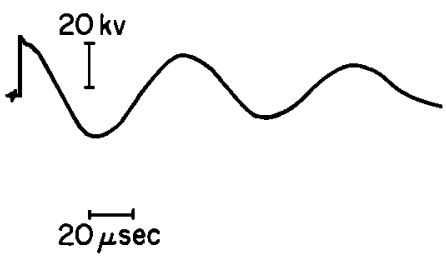

C

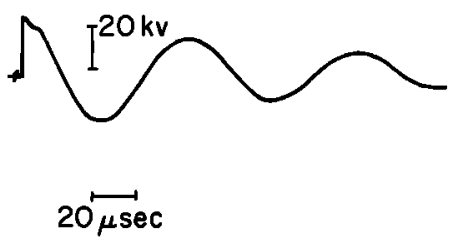

b

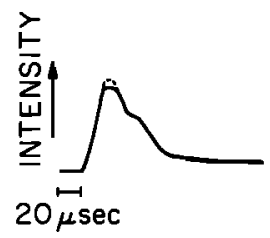

d

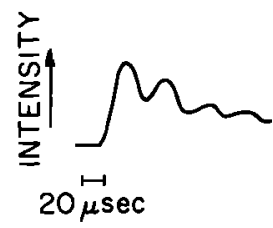

Fig. 4. Time variability of high-intensity point light source. (a) Voltage between ignitron anode and ground. The capacitor bank is charged to $19.5 \mathrm{kv}$. The ground electrode diameter is 1/16 inch. (b) Intensity of light emitted by source in $(a)$. (c) Same as (a) with a ground electrode diameter of $1 / 8$ inch. $(d)$ Intensity of light emitted by source in $(c)$. 


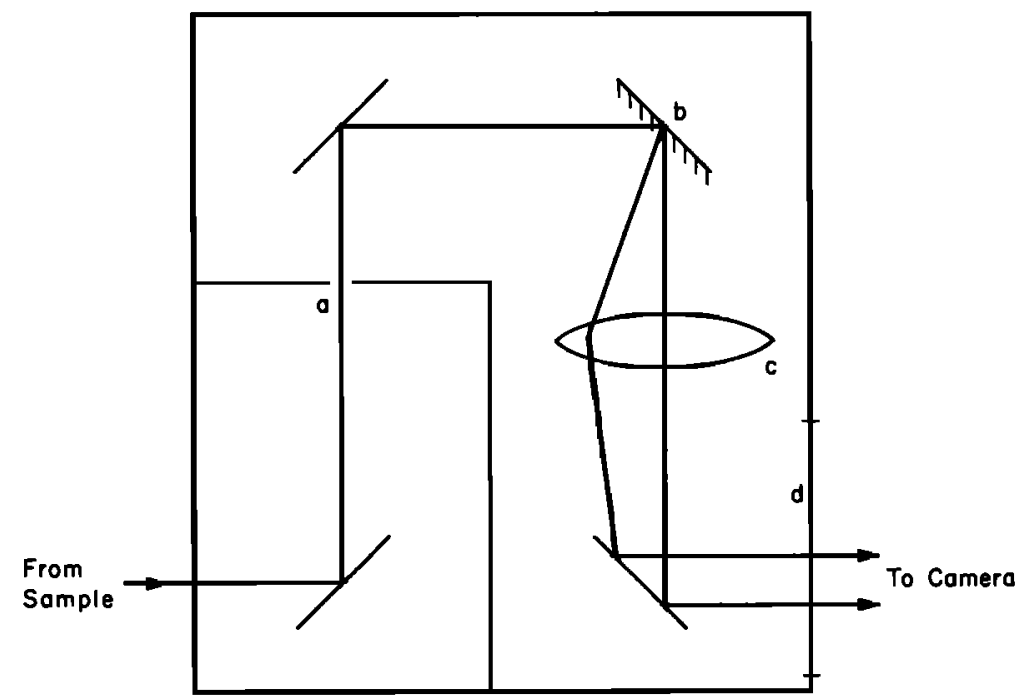

Fig. 5. Schematic representation of spectrograph used for measuring optical absorption spectra of shocked solids. (a) Entrance slit $(0.8 \mathrm{~mm})$. (b) Diffraction grating (Bausch and Lomb 35-53-04-350), 600 lines $/ \mathrm{mm}, 13^{\circ}$ blaze. (c) An $f / 2.7$ 13.5-mm lens. (d) Exit slit (0.5 mm wide).

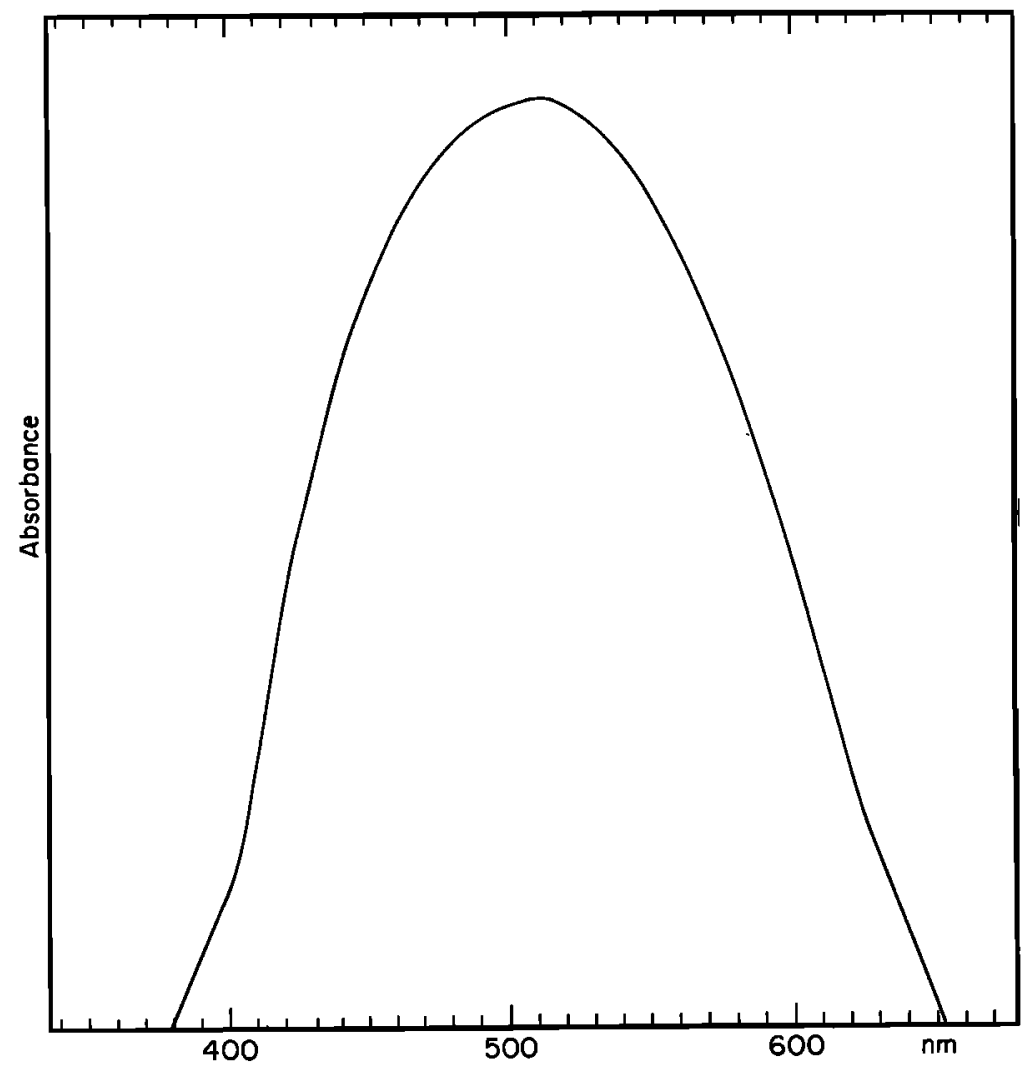

Fig. 6. Spectral response of TRW model 1D streak camera combined with the optics used in this study. 


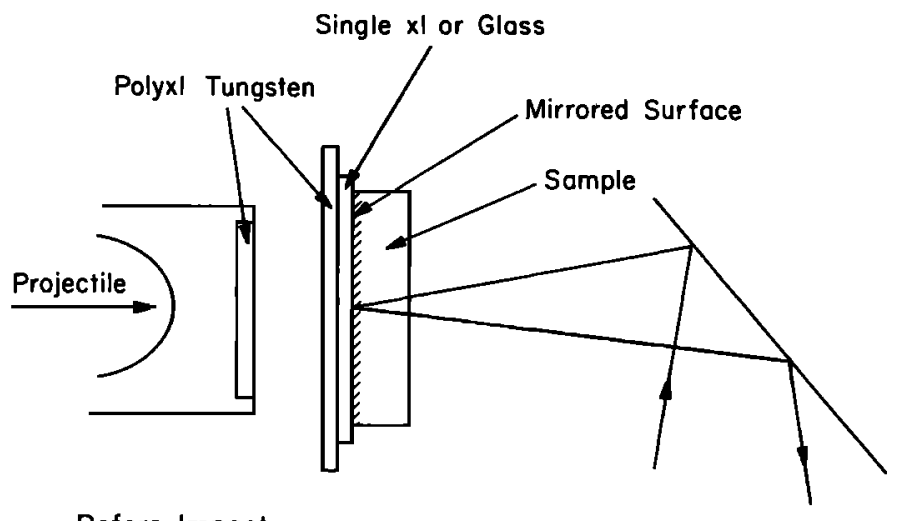

Before Impact

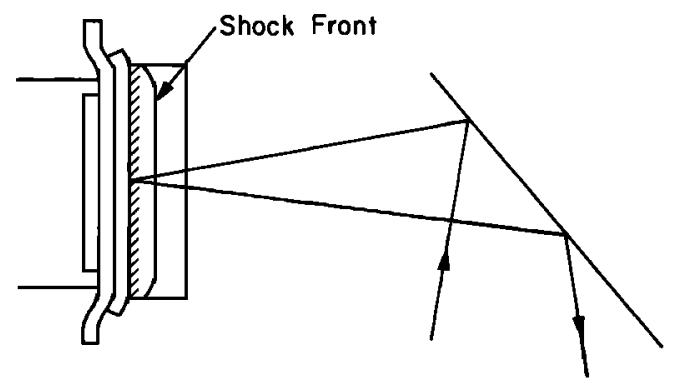

\section{During Shock Transit}

Fig. 7. Detail of the sample arrangement before impact (above) and during shock transit (below) showing light path and regions of the sample studied.

mounted on a thin slab of single-crystal material or glass with the side toward the sample polished. This extra layer smooths the shock front, which is optically rough when it leaves the polycrystalline material of the projectile and driver plate. Without this layer, the mirrored surface of the sample ceases to be a good specular reflector when the shock passes it. To date, samples as thin as $3 \mathrm{~mm}$ and as small as $12 \mathrm{~mm}$ in diameter have been successfully used. Thinner samples could be used by sandwiching them between glass, sapphire, periclase, or the like.

The light path within the target is also indicated in Figure 7. The near normal $\left(61 \mathbf{2}^{\circ}\right)$ incidence reduces reflection losses at the free surface, and the double path length allows greater total absorption than a single transit. The light path after impact is also indicated. In this case the path samples both high- and low-pressure regions. As the shock progresses through the sample, the low-pressure spectrum fades out and is gradually replaced by the highpressure spectrum.

This system has been used successfully to obtain spectra of periclase $(\mathrm{MgO})$, soda lime glass, and ruby. Data for periclase and ruby are discussed below.

\section{High-Pressure Absorption Spectrum of MaO}

The spectrum of periclase at zero pressure is completely featureless in the visible region. A study of the spectrum of shock-compressed $\mathrm{MgO}$ was undertaken to determine the feasibility of using the material as a 'window' to permit the measurement of spectra in thinner samples and at higher pressures (by using a reflected shock technique). To be useful for this application, the material must retain its transparency during shock compression. In addition, such a study is of interest in order to better interpret spectra of $\mathrm{MgO}$ shocked to high pressures and 
recovered. Gager et al. [1964] have observed $\mathrm{F}$ centers in $\mathrm{MgO}$ recovered from a shock pressure in excess of $500 \mathrm{~kb}$. Such features should be observable in these absorption spectra whether they are produced on loading or unloading.

Figure 8 shows a record of the absorption spectrum of $\mathrm{MgO}$ shocked to $465 \pm 10 \mathrm{~kb}$ final pressure. The pressure is inferred from the impact velocity and the known Hugoniots of the tungsten flyer and driver plate [McQueen et al., 1970] and sample [Carter et al.; 1971]. Such a shock should be preceded by an elastic precursor with a normal stress of about $90 \mathrm{~kb}$ [Ahrens, 1966]. The difference in velocity of the two shocks should be about $1.5 \mathrm{~mm} / \mu \mathrm{sec}$, the elastic shock traveling at $10.1 \mathrm{~mm} / \mu$ sec. In the upper part of the picture (region A) we see the spectrum of the unshocked $\mathrm{MgO}$ followed by a sharp decrease in intensity, indicating the arrival of the shock at the internal mirror surface. It is not possible with this experiment to separate the three possible causes of this decrease, which are (1) absorption in the shock front, (2) degradation of the mirror by the shock, or (3) rotation of the mirror by an oblique shock impact. Any or all of these features could lead to observed featureless decrease in light intensity. Below this discontinuity (region B) the spectrum is progressively changing from that of unshocked $\mathrm{MgO}$ to that of shocked $\mathrm{MgO}$. The opacity of the shocked material is greater than that of the unshocked material, but no spectral features are apparent. This may be an intrinsic effect due to compression of $\mathrm{MgO}$ to $465 \mathrm{~kb}$, or it may be due to scattering off of numerous shockinduced imperfections in the crystal. In the absence of any other data, we favor the latter cause.

There are two discontinuities in rapid succession at the end of region $B$. These are attributed to arrivals of the elastic and plastic shocks at the free surface of the sample, which can be expected to degrade the surface sufficiently to yield a substantial (featureless) decrease in light transmission. From the time separation between mirror encounter and free surface emergence we can calculate the shock velocities to be $8.0 \pm 0.5$ and $9.9 \pm 0.1 \mathrm{~mm} / \mu$ sec for the plastic and elastic waves, respectively. These values are in very good agreement with those of

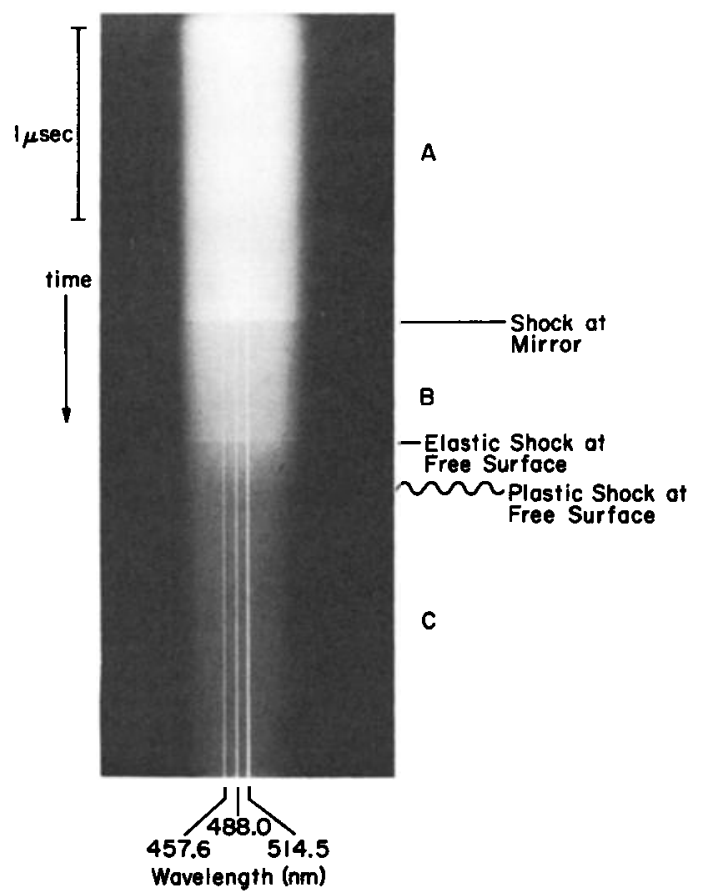

Fig. 8. Absorption spectrum of periclase $(\mathrm{MgO})$ shocked to $465 \mathrm{~kb}$.

Ahrens [1966], especially in view of the rather diffuse nature of the second arrival in Figure 8.

In region $\mathrm{C}$ of the record we have the spectrum of $\mathrm{MgO}$ while it unloads from $465 \mathrm{~kb}$. There is no change apparent across this region, indicating that no changes in the opacity of periclase occur during the first $1 \frac{1}{2} \mu$ sec of unloading. This is sufficient time to permit complete unloading of the $\mathrm{MgO}$ back to the mirror (unless the low-pressure shock wave reflected from the rear surface of the flyer plate interferes). If color centers have been produced in this event, they must be few in number, in some other spectral region, or not yet in their ground state. It is concluded that shock pressures greater than $465 \mathrm{~kb}$ are required to produce substantial populations of color centers in periclase. Because of the qualitative nature of intensity measurements with the present system, the term substantial cannot be more qualitatively defined.

\section{RUBY SPECTRA}

Although $\mathrm{Fe}^{2+}$ is by far the most abundant of the transition metal ions in the mantle, its 
most intense crystal field absorptions in most coordinations expected in the mantle are in the near infrared. This is a spectral region that cannot be studied by the present spectrographic system, and so the effects of large compressions on the absorption spectrum of single-crystal ruby $\left(\mathrm{Cr}^{3+}: \mathrm{Al}_{2} \mathrm{O}_{3}\right)$, which is in a spectral region accessible to the system, were studied instead. We believe that the behavior of $\mathrm{Fe}^{2+}$ can be inferred from such data by using techniques such as those of Gaffney [1972]. The corundum $\left(\mathrm{Al}_{2} \mathrm{O}_{3}\right)$ structure is, of course, a close analog to the ilmenite structure. This structure is probably the form in which the pyroxene and garnet minerals exist in a major part of the lower mantle. The present experiments span the range from 147 to $530 \mathrm{~kb}$. The highest pressure is more than three times greater than the maximum attained in static compression experiments on corundum [Stephens and Drickamer, 1961]. Such measurements permit a determination of the local environment about the $\mathrm{Cr}^{\mathrm{s}+}$ impurities in the corundum $\left(\mathrm{Al}_{2} \mathrm{O}_{\mathbf{s}}\right)$ lattice. The data are presented below and discussed in light of the hydrostatic spectral studies and the recent Hugoniot measurements on sapphire [Graham and Brooks, 1971].

The principal absorptions in ruby arise from the $\mathrm{Cr}^{\mathrm{s+}}$ ion's substituting in $\mathrm{Al}$ sites in corundum. These sites are nearly octahedral with some trigonal distortion. In the pure octahedral field the $\mathrm{F}$ ground state of $\mathrm{Cr}^{3+}$ splits into ${ }^{4} \mathrm{~A}_{2}$, ${ }^{-} T_{2}$, and ${ }^{~} T_{1}$ [Tanabe and Sugano, 1956]. The observed absorptions in the visible correspond to the electronic transitions " $\mathrm{A}_{2} \rightarrow{ }^{ } \mathrm{T}_{2}$ at about $18,000 \mathrm{~cm}^{-1}$ and ${ }^{~} A_{2} \rightarrow{ }^{'} T_{1}$ at about $25,000 \mathrm{~cm}^{-1}$. The trigonal field splits the excited state ${ }^{~} T_{2}$ into ${ }^{4} A_{1}$ and ${ }^{4} E$ states and the state ${ }^{4} T_{1}$ into ${ }^{~} A_{2}$ and ${ }^{4} E$ states with separations of about $500 \mathrm{~cm}^{-1}$, but this is too small (relative to the widths of the absorptions) to be determined in the unpolarized spectra reported here [Stephens and Drickamer, 1961, Figure 1].

The effect of hydrostatic pressures up to 150 $\mathrm{kb}$ on the spectra of ruby has been studied by Stephens and Drickamer [1961]. They found that $D q$ increased proportional to $1 / r^{5}$ as $r$, the mean interatomic distance, decreased. This is exactly the behavior predicted for a point charge model [Gaffney, 1972]. Since Stephens and Drickamer measured the positions of both the ${ }^{4} A_{2} \rightarrow{ }^{4} T_{2}$ and ${ }^{4} A_{2} \rightarrow{ }^{4} T_{1}$ transitions up to
$120 \mathrm{~kb}$, they were also able to determine that one of the Racah parameters $(B)$ decreases on compression approximately as $r^{3}$. (There is no model for predicting the change of $B$ or $C$ with interatomic distance.) From the polarization dependence of the spectra they found that the trigonal splitting of the ${ }^{~} T_{2}$ and ${ }^{4} T_{1}$ states increased on compression for pressures over 60 $\mathrm{kb}$. The value extrapolated from 120 to $150 \mathrm{~kb}$ would be about $950-1000 \mathrm{~cm}^{-1}$. It was not possible in our experiments to determine the variation of the Racah parameters in ruby at larger compressions because the spectrograph could not follow the position of the ${ }^{4} \mathrm{~A}_{2} \rightarrow{ }^{\mathrm{C}} \mathrm{T}_{1}$ transition into the shocked region as a result of the spectral sensitivity of the streak camera photocathode.

The samples studied here were single-crystal pink ruby $\left(0.5 \% \mathrm{Cr}: \mathrm{Al}_{2} \mathrm{O}_{3}\right)$ disks $6 \mathrm{~mm}$ thick and $22 \mathrm{~mm}$ in diameter with the crystallographic $c$ axis at $60^{\circ}$ to the flat surfaces. They were flat to one wave and polished with one surface aluminized. Fabrication was done by the vendor, Union Carbide, Crystal Products Division. An unpolarized absorption spectrum of one of the samples taken at room temperature is shown in Figute 9.

Spectra were measured at three values of normal shock stress, one below the elastic limit $(147 \mathrm{~kb})$ and two above (430 and $530 \mathrm{~kb}$ ). The data obtained from these three experiments are summarized in Table 2. Figure 10 shows a typical photographic record. These photographic negatives were digitized and stored on tape by the Image Processing Laboratory of the Jet Propulsion Laboratory and then computer processed to reduce the noise level.

To obtain the positive of the absorption peaks under shock compression, microdensitometer traces across the film were differenced to show the change in the absorption between two traces, one taken in the low-pressure region (of the film) and the other taken in the highpressure region. If the earlier trace is subtracted from the later one, absorption maximums in the low-pressure region appear as negative features, whereas those in the highpressure region will be positive features.

To evaluate the results summarized in Table 2 , one must distinguish between absorptions in the volumes ahead of and behind the shock front, on the one hand, and at interfaces such 


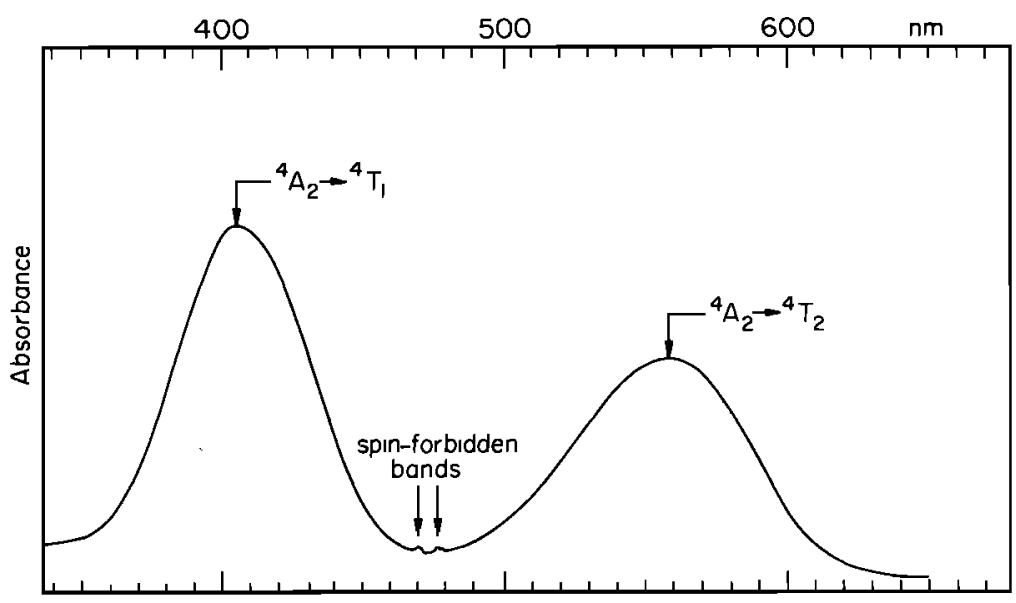

Fig. 9. Absorption spectrum of pink ruby $\left(\mathrm{Al}_{2} \mathrm{O}_{3}: 0.05 \% \quad \mathrm{Cr}_{2} \mathrm{O}_{3}\right)$ at zero pressure.

as the internal mirror, the shock front, and the free surfaces on the other. In principle, this is easy to do, since the former will have intensities that vary with time, whereas the latter will not vary during the experiment. In practice, it is often difficult to make such a decision because the signal-to-noise ratio is so low that it is difficult to obtain meaningful information about intensities. In the present case the highest energy absorption observed at $147 \mathrm{~kb}$ was time invariant, so that one can conclude that either the elastically shocked mirror or the elastic front produces this feature. This feature is not observed in the other spectra.

The energy of the ${ }^{4} A_{2} \rightarrow{ }^{4} T_{2}$ transition is just $10 D q$, and so we can plot the data of Table 2 against relative volume as determined by Graham and Brooks [1971] to determine the variation of $D q$ with interatomic distance (Figure 11). There are two distinct regions of behavior. Below the Hugoniot elastic limit (HEL) there are very great nonhydrostatic stresses. On the basis of the discussion by Graham and Brooks, the difference in principal stresses behind the shock front at $147 \mathrm{~kb}$ normal stress is about $90 \mathrm{~kb}$. It is to be expected, therefore, that the local symmetry about the $\mathrm{Cr}^{3+}$ ions is considerably distorted from that of the octahedral case. This distorted symmetry is exactly what is found below the HEL. The usually triply degenerate absorption due to ${ }^{4} A_{2} \rightarrow{ }^{4} T_{2}$ is split by more than 3730 $\mathrm{cm}^{-1}$, almost four times the value extrapolated from hydrostatic experiments.
Above the HEL we find a very different situation. Now there is only one absorption discernible, indicating that the splitting of the ${ }^{4} \mathrm{~T}_{2}$ state due to nonoctahedral fields is less than about $800 \mathrm{~cm}^{-1}$. (The absorption due to the elastically shocked region is not discernible because at any given moment less than $20 \%$ of the material behind the elastic shock is ahead of the second shock. The shock velocities for the elastic and second waves are about 11 and $9 \mathrm{~mm} / \mathrm{sec}$, respectively.) This means that the strain must be nearly isotropic at stresses of the order of $400-500 \mathrm{~kb}$ and therefore that the nonhydrostatic component of stress must be fairly small. If the splitting of ${ }^{4} \mathrm{~A}_{2} \rightarrow{ }^{4} \mathrm{~T}_{2}$ band

TABLE 2. Spectral Data for Ruby

\begin{tabular}{|c|c|c|c|}
\hline Shock & $\begin{array}{l}\text { Pressure, } \\
\mathrm{kb}\end{array}$ & $\begin{array}{c}\text { Absorption Band, } \\
\mathrm{nm}\end{array}$ & Assignment \\
\hline & 0 & $\begin{array}{l}559^{*} \\
546^{*}\end{array}$ & $\begin{array}{l}{ }^{4} \mathrm{~A}_{2} \rightarrow{ }^{4} \mathrm{~F} \pi \\
{ }^{4} \mathrm{~A}_{2} \rightarrow{ }^{4} \mathrm{~A}_{1} 11\end{array}$ \\
\hline 147 & $7 \pm 3$ & $\begin{array}{l}478 \pm 5 \dagger \\
524 \pm 10 \dagger \\
581 \pm 4 \dagger \\
446 \pm 3 \S\end{array}$ & ${ }^{4} A_{2} \rightarrow{ }^{4} T_{2}+$ \\
\hline 430 & \pm 10 & $460 \pm 10$ & ${ }^{4} A_{2} \rightarrow{ }^{4} T_{2}$ \\
\hline 530 & \pm 10 & $411 \pm 12$ & ${ }^{4} \mathrm{~A}_{2}+{ }^{4} \mathrm{~T}_{2}$ \\
\hline
\end{tabular}

*Stephens and Drickamer [1961].

†Triple degeneracy removed by nonhydrostatic strain around $\mathrm{Cr}^{+3}$ site.

STime invariant absorption arising from either shock front or reflecting mirror.

"Perpendicular to $c$ axis.

"Parallel to $c$ axis. 
is linear in the shear stress, then, by comparison with the data at $147 \mathrm{~kb}$, the shear stress above the HEL must be less than about $20 \mathrm{~kb}$. Thus these experiments confirm, by a completely different method, the conclusion of Graham and Brooks [1971] that sapphire loses most of its shear strength when it is shocked above the HEL. This experimental technique, with improved accuracy, has potential as an internal strain gage for detecting anisotropic strains in shock studies.
The measured value of $D q$ can be compared with that predicted by a point charge model [McClure, 1959], if it is assumed that the local compressibility about the $\mathrm{Cr}^{\mathrm{a}+}$ ion is equal to the bulk compressibility of its host $\mathrm{Al}_{2} \mathrm{O}_{3}$. For a perfect octahedron such a model predicts that $D q$ should be proportional to $V^{-5 / 3}$, where $V$ is the molar volume of sapphire. Stephens and Drickamer [1961] found that this model worked very well for hydrostatic compression up to $150 \mathrm{~kb}$ ( $3.5 \%$ compression) for $\mathrm{Cr}^{8+}$ in

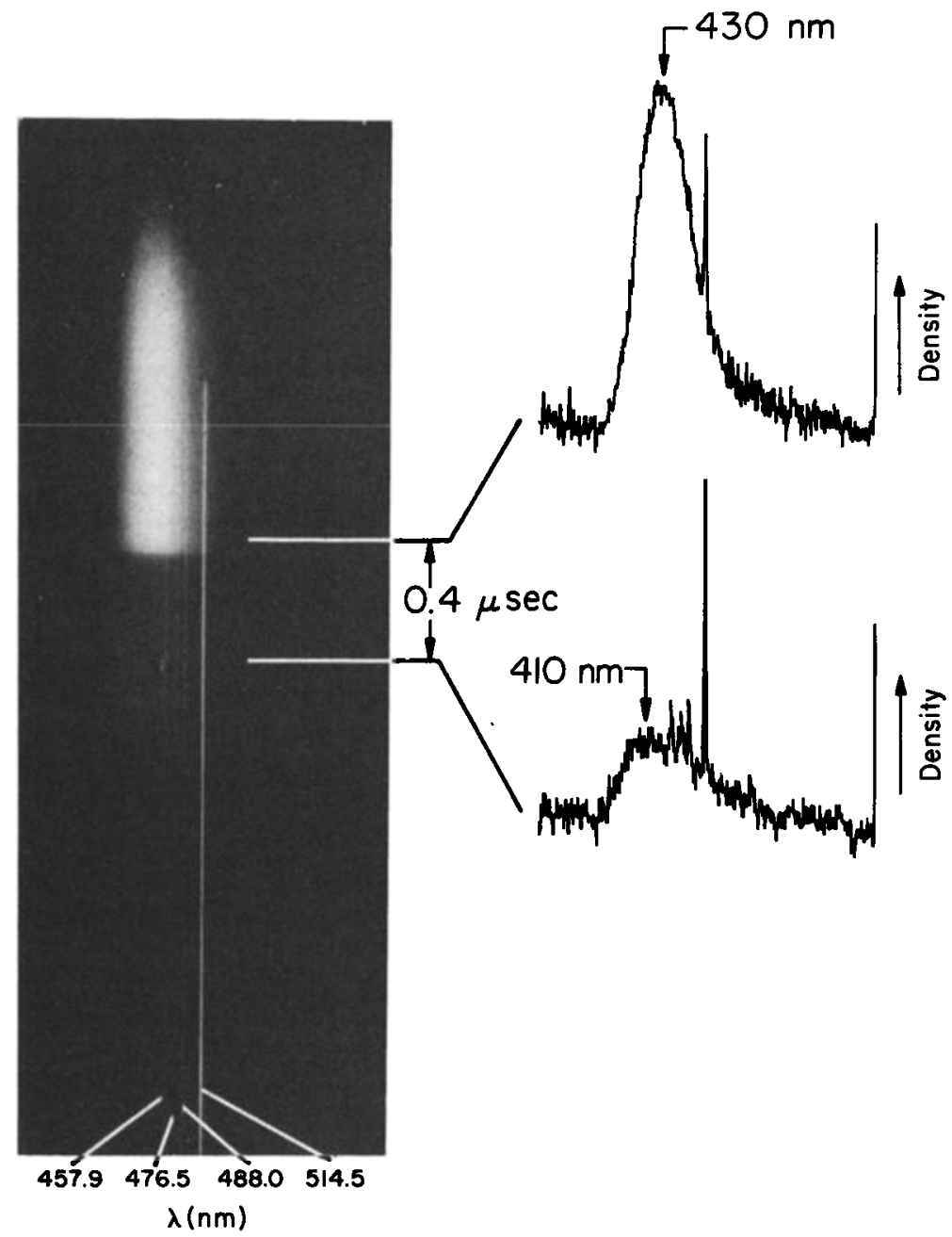

Fig. 10. Spectrum of pink ruby shocked to $430 \mathrm{~kb}$. This is essentially a transmission spectrum of the sample. The four vertical lines are the emission lines of a pulsed argon laser used for wavelength calibration. The optical density of the negative on two scans is plotted on the right. The shift in the transmitted light peak from $\sim 450 \mathrm{~nm}$ in the unshocked crystal to $\sim 400 \mathrm{~nm}$ in the shocked sample arises from the shift in the ${ }^{4} \mathrm{~A}_{\mathrm{M}} \rightarrow{ }^{4} \mathrm{~T}_{2}$ absorption from 555 to $460 \mathrm{~nm}$ and the shift of the $500-\mathrm{nm}\left({ }^{4} \mathrm{~A}_{2} \rightarrow{ }^{4} \mathrm{~T}_{1}\right)$ band out of the present spectral window (Figure 6). 


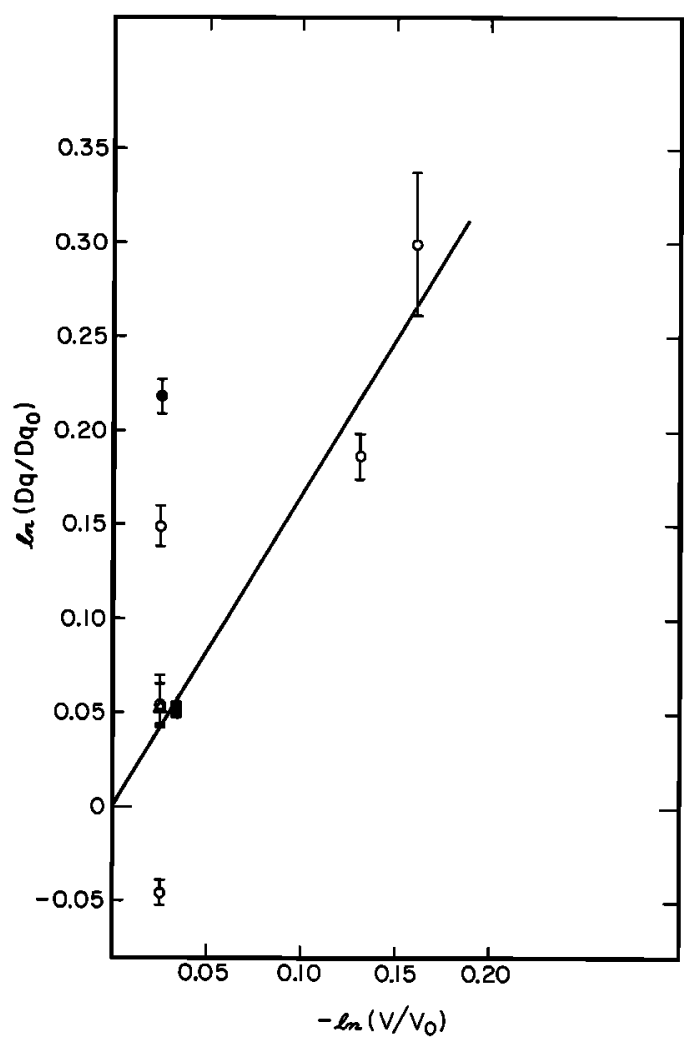

Fig. 11. Observed absorption bands and the variability of $D q$ with $R$ for shock-loaded rubies. Hydrostatic spectral data of Stephens and Drickamer are shown for comparison. The diagonal line is the variation of $D q$ with $V$ predicted by the point charge model. Open circles indicate absorption behind the shock front $\left({ }^{4} A_{9} \rightarrow{ }^{\top} T_{8}\right)$; solid circle, absorption in shock front; open triangle, average $\left(D q / D q_{0}\right)$ for transitions to nongenerate ${ }^{2} T$, states; solid rectangle, upper limit of hydrostatic data [Stephens and Drickamer, 19611 .

$\mathrm{Al}_{2} \mathrm{O}_{3}$ and up to $\sim 60 \mathrm{~kb}$ for $\mathrm{Ti}^{3+}, \mathrm{V}^{3+}, \mathrm{Ni}^{2+}$, and $\mathrm{Ni}^{3+}$ in $\mathrm{Al}_{2} \mathrm{O}_{3}$ [Minomura and Drickamer, 1961]. However, when a transition metal ion was substituted in $\mathrm{MgO}$, the increase in $D q$ was found to be somewhat more rapid than $V^{-5 / 3}$ [Minomura and Driclcamer, 1961]. Increases of $D q$ greater than the $V^{-5 / 3}$ law of from 10 to $60 \%$ as observed in $\mathrm{MgO}$ are probably more likely to occur if the substituting transition metal ionic radius is markedly smaller than that of the host element normally occupying the cation site. If the substituting ion is larger than that of the host element normally occupying the site, $D q$ will likely be somewhat less than that predicted by the $V^{-s / s}$ law, as in the case of high-spin $\mathrm{Fe}^{++}$[Shankland, 1968]. In addition to size, of course, covalency and relocation of the lattice in the vicinity of the impurity will be important.

The present results demonstrate the usefulness of the point charge model for determining the effect of volume compressions of nearly $15 \%$ on the crystal field spectrum of $\mathrm{Cr}^{3+}$ in $\mathrm{Al}_{2} \mathrm{O}_{3}$. To the extent that the corundum type of close-packed structure is typical of some of the mineral phases of the lower mantle, we conclude that the effect of pressure on the crystal field absorption spectrum is at least approximately predictable when this model is used.

Finally, the good agreement of the present data with those of Stephens and Drickamer demonstrates that above the HEL the shock states produced in $\mathrm{Al}_{2} \mathrm{O}_{3}$ are essentially hydrostatic.

Acknowledgments. Many helpful suggestions in experiment design were made by $\mathbf{H}$. F. Swift and E. J. Bunker. We appreciate the experimental help of J. Lower, D. Johneon, and H. Richeson. Conversations with G. Rossman, T. J. Shankland, and $R$. Vaughn were most helpful and are gratefully acknowledged.

This work was supported by the National Science Foundation under grant NSF GA 21396.

\section{REFERENCES}

Ahrens, T. J., High-pressure electrical behavior and equation of state of magnesium oxide from shock wave measurements, J. Appl. Phys., 97, 2532-2541, 1966.

Burns, R. G., Crystal field spectra and evidence of ordering in olivine minerals, Amer. Mineral., 65, 1608-1632, 1970.

Carter, W. J., S. P. Marsh, J. N. Fritz, and R. G. McQueen, The equation of state of selected materials for high-pressure references, in Accum rate Characterization of the High-Pressure Environments, Spec. Publ. 326 , edited by E. C. Lloyd, pp. 147-158, National Bureau of Standards, Washington, D.C., 1971.

Clark, S. P., Jr., Radiative transfer in the earth's mantle, Eos Trans. AGU, 88, 931-938, 1957.

David, H. G., and A. H. Ewald, Photographic observations on shock waves in liquids, Aust. J. Appl. Sci., 11, 317-320, 1960.

Gaffney, E. S., Crystal field effects in mantle minerals, Phys. Earth Planet. Interiors, 6, 385390, 1972.

Gager, W. B., M. J. Klein, and W. H. Jones, The generation of vacancies in $\mathrm{MgO}$ single crystals by explosive shock, Appl. Phys. Lett., 5, 131$132,1964$. 
Graham, R. A., and W. P. Brooks, Shock-wave compression of sapphire from 15 to $420 \mathrm{kbar}$ : The effects of large anisotropic compressions, J. Phys. Chem. Solids, 32, 2311-2330, 1971.

McClure, D. S., Electronic spectra of molecules and ions in crystals, 2, Spectra of ions in crystals, Solid State Phys., 9, 399-525, 1959.

McQueen, R. G., S. P. Marsh, J. W. Taylor, J. N. Fritz, and W. J. Carter, The equation of state of solids from shock wave studies, in $\mathrm{High}$ Velocity Impact Phenomena, edited by R. Kinslow, pp. 294-419, Academic, New York, 1970.

Minomura, S., and H. G. Drickamer, Effect of pressure on the spectra of transition metal ions in $\mathrm{MgO}$ and $\mathrm{Al}_{2} \mathrm{O}_{3}, J$. Chem. Phys, 35, 903907, 1961.

Pitt, G. D., and D. C. Tozer, Radiative heat transfer in dense media and its magnitude in olivines and some other ferromagnesian minerals under typical upper mantle conditions, Phys. Earth Planet. Interiors, 2, 189-199, 1970.

Preonas, D. D., and H. F. Swift, A high-intensity point light source, paper presented at 9 th International Congress on High-speed Photog- raphy, Univ. of Denver Res. Inst., Denver, Colo., December 1970.

Schatz, J. F., and G. Simmons, Thermal conductivity of earth materials at high temperatures, J. Geophys. Res., 77, 6966-6983, 1972.

Shankland, T. J., Pressure shifts of absorption bands in $\mathrm{MgO}: \mathrm{Fe}^{2+}$ and the dynamic JahnTeller effect, J. Phys. Chem. Solids, 89, 1907$1909,1968$.

Stephens, D. R., and H. G. Drickamer, Effect of pressure on the spectrum of ruby, J. Chem. Phys., 35, 427-429, 1961.

Tanabe, $Y$., and $\mathbf{S}$. Sugano, On the absorption spectra of complex ions, 3 , The calculation of the crystalline field strength, J. Phys. Soc. Jap., 11, 864-877, 1956.

Yakusheva, O. B., V. V. Yakushev, and A. N. Dremin, The opacity mechanism of shockcompressed organic liquids, High Temp. High Pressure, 3, 261-266, 1971.

(Received November 13, 1972; revised April 13, 1973.) 